\title{
Chemical pleurodesis with Viscum album L. extract for secondary spontaneous pneumothorax in elderly patients
}

\author{
Jong Duk Kim ${ }^{1} \wedge$, Jae Won Choi ${ }^{1} \wedge$, Hyun Oh Park ${ }^{1}$, Chung Eun Lee ${ }^{1} \wedge$, In Seok Jang ${ }^{1}$, \\ Jun Young Choi ${ }^{1} \wedge$, Dong Hoon Kang ${ }^{2} \wedge$, Jae Jun Jung ${ }^{2} \wedge$, Jun Ho Yang ${ }^{2} \wedge$, Sung Ho Moon ${ }^{2} \wedge$, \\ Joung Hun Byun ${ }^{2} \wedge$, Sung Hwan $\mathrm{Kim}^{2} \wedge$, Jong Woo Kim ${ }^{2 \wedge}$
}

${ }^{1}$ The Department of Cardiothoracic surgery, School of Medicine, Gyeonsang National University, Gyeongsang National University Hospital, Jin-Ju, Republic of South Korea; ${ }^{2}$ The Department of Cardiothoracic surgery, School of Medicine, Gyeonsang National University, Gyeongsang National University Chang-Won Hospital, Chang-Won, Republic of South Korea

Contributions: (I) Conception and design: JD Kim, IS Jang; (II) Administrative support: JW Choi, CE Lee, JH Yang; (III) Provision of study materials or patients: JY Choi, SH Moon, HO Park; (IV) Collection and assembly of data: SH Kim, JH Kim, JH Byun; (V) Data analysis and interpretation: DH Kang, JJ Jung; (VI) Manuscript writing: All authors; (VII) Final approval of manuscript: All authors.

Correspondence to: Jong Duk Kim. Gyeongsang National University Hospital, Jin-Ju, Republic of South Korea. Email: frogeye1@hanmail.net.

\begin{abstract}
Background: Secondary spontaneous pneumothorax is generally managed by surgery, if pneumothorax was not improved following chest tube insertion or in the event of persistent air leakage lasting more than 5 days. However, if surgery is not an option, chemical pleurodesis with sclerosants can be performed. Several sclerosants have been used in the chemical pleurodesis of secondary spontaneous pneumothorax, However, there is still controversy for what is the ideal sclerosant for Secondary spontaneous pneumothorax. The use of Viscum album L. for chemical pleurodesis in patients with secondary spontaneous pneumothorax aged $>65$ years has not been described to date, despite its extensive use. The authors tried to find out the effect of Viscum album L. for sclerosant for Secondary spontaneous pneumothorax in elder.
\end{abstract}

Methods: This retrospective analysis examined 25 patients (aged $>65$ years) with secondary spontaneous pneumothorax with persistent air leakage who underwent chemical pleurodesis with Abnova Viscum- $\mathrm{F}^{\circledR}(V$. album L.).

Results: The duration of chest tube drainage was 5.08 days after chemical pleurodesis. Adverse effects related to chemical pleurodesis with Abnova Viscum- $\mathrm{F}^{\circledR}$ were fever (7/25), pain (4/25), leukocytosis (10/25), and dyspnea with desaturation (7/25); however all the patients recovered without sequela and were subsequently discharged.

Conclusions: The present study demonstrated the successful use of chemical pleurodesis with $V$. album L. in the management of elderly patients with secondary spontaneous pneumothorax. Because of the high probability of dyspnea with desaturation in the elderly, caution must be exercised.

Keywords: Pneumothorax; pleurodesis; Viscum album

Submitted Feb 05, 2020. Accepted for publication Sep 10, 2020.

doi: $10.21037 /$ jtd-20-708

View this article at: http://dx.doi.org/10.21037/jtd-20-708

^ ORCID: Jong Duk Kim: 000000030268 1674; Jae Won Choi: 0000-0003-3984-0296; Hyun Oh Park: 0000-0003-1302-6456; Chung Eun Lee: 0000-0003-4469-7201; In Seok, Jang: 0000-0003-1929-6238; Jun Young Choi: 0000-0001-7774-8541; Dong Hoon Kang: 00000001-7837-1360; Jae Jun Jung: 0000-0002-0736-390X; Jun Ho Yang: 0000-0002-7508-5307; Sung Ho Moon: 0000-0001-8043-1588; Joung Hun Byun: 0000-0003-1909-664x; Sung Hwan Kim: 0000-0002-6888-774X; Jong Woo Kim: 0000-0 003-2578-9821. 


\section{Introduction}

Recurrent secondary spontaneous pneumothorax may be managed by chemical pleurodesis, despite its limited use, and it is recommended only when a patient is either unwilling or unable to undergo surgery (1). Several sclerosants have been used in the chemical pleurodesis of secondary spontaneous pneumothorax, including tetracycline, doxycycline, minocycline, and bleomycin; moreover, pleurodesis with povidone-iodine and auto-blood have also been performed at various institutions in several countries (2-6). An ideal chemical pleurodesis should be effective, have less complications, and be cost effective (3). Several studies have indicated that chemical pleurodesis with talc is impressively effective (7-9). Chemical pleurodesis using extracts from the mistletoe plant Viscum album $\mathrm{L}$. was demonstrated to be effective against malignant pleural effusion $(10,11)$. To the best of our knowledge, the use of $V$. Album L. in the chemical pleurodesis of patients with secondary spontaneous pneumothorax aged $>65$ years has not been described, despite its extensive use.

Therefore, the present study aimed to present the findings of using chemical pleurodesis with $V$. Album L. in the management of secondary spontaneous pneumothorax in elderly patients. We present the following article in accordance with the STROBE reporting checklist (available at http://dx.doi.org/10.21037/jtd-20-708).

\section{Methods}

\section{Patients}

From April 2015 to December 2018, 344 patients who were diagnosed with secondary spontaneous pneumothorax at our hospital were considered either for surgery or chemical pleurodesis if pneumothorax was not improved following chest tube insertion on radiography or persistent air leakage lasting more than 5 days was identified. If secondary spontaneous pneumothorax could be resolved by bullectomy, then video-assisted thoracoscopic surgery (VATS) was performed as a routine management approach. In the case of secondary spontaneous pneumothorax in elderly patients, severe emphysematous change in the whole lung field was often observed on chest computed tomography as an underlying pulmonary disease. Under this condition or if comorbidities and poor performance was identified and patient refused to undergo surgery, then secondary spontaneous pneumothorax was resolved through chemical pleurodesis.
Among the 344 patients, 175 underwent VATS bullectomy and 120 underwent chest tube insertion. The remaining 49 patients underwent bedside chemical pleurodesis with $V$. Album L. (Abnova Viscum-F, HankookAbnova, Seoul, Korea). Among the 49 patients, 25 were aged $\geq 65$ years, and their clinical records were retrieved for this retrospective study, which was approved by Institutional Review Board of Gyeongsang National University Medical Center (No. 2019-06-023). The study was conducted in accordance with the Declaration of Helsinki (as revised in 2013). Informed consent was taken from all the patients.

\section{Chemical pleurodesis}

Patients were administered $20 \mathrm{~mL}$ of $2 \%$ lidocaine as an analgesic, which was mixed in $50 \mathrm{cc}$ normal saline solution and injected into the rubber portion of the chest tube. This was followed by injection of Abnova Viscum- $\mathrm{F}^{\circledR}(60 \mathrm{mg})$ in $50 \mathrm{cc}$ normal saline into the chest tube, which was kept at a height of $40-60 \mathrm{~cm}$ above the patient, so as to prevent direct flow of Abnova Viscum- $\mathrm{F}^{\circledR}$ into the chest bottle when the patient was in the supine, prone, or lotus positions for 2 hours. Subsequently, the chest tube was kept below the level of patient to allow natural drainage of the injected Abnova Viscum- $\mathrm{F}^{\circledR}$. The procedure was deemed a success and the chest tube was removed if pneumothorax was not observed by chest $\mathrm{X}$-ray and the chest bottle drainage was maintained below $150 \mathrm{cc} /$ day for 2 days after chemical pleurodesis. If air leakage persisted after the procedure, the patient underwent repleurodesis every 3 days.

\section{Statistical analysis}

Continuous variables were presented as means, median, range and standard deviation. Categorical variables were presented as frequency with the associated percentages. All statistical analyses were performed using IBM SPSS software version 22.0 (IBM Corp. Armonk, NY, USA).

\section{Results}

\section{Patient characteristics}

Among the 25 patients aged $\geq 65$ years, 22 were males and median age was 78.56 years (range, $65-91$ years). Among the patients, 15 were affected on the right side and 10 on the left (Table 1). Of the 25 patients with secondary spontaneous pneumothorax, 56\% $(\mathrm{n}=14)$ had co-morbid lung disease, 
Table 1 Patient characteristics

\begin{tabular}{lc}
\hline Characteristics & Total $(\mathrm{n}=25)$ \\
\hline Age, mean [range] & $78.56[65-91]$ \\
Sex (male/female) & $22 / 3$ \\
Height $(\mathrm{cm})$, mean [range] & $164[147-181]$ \\
BMl $\left(\mathrm{kg} / \mathrm{m}^{2}\right)$, mean (range) & $20.42(15.86-25.79)$ \\
Affected side & \\
Right & 10 \\
Left & 15 \\
Smoking history (pack-year ), mean & 16.36 \\
\hline
\end{tabular}

Table 2 Co-existing pulmonary disease

\begin{tabular}{lc}
\hline Diagnosis & Total $(\mathrm{n}=25)$ \\
\hline Chronic obstructive pulmonary disease & $14(56 \%)$ \\
Previous pulmonary tuberculosis & $7(28 \%)$ \\
Interstitial lung disease & $2(8 \%)$ \\
Lung cancer & $1(4 \%)$ \\
Asthma & $1(4 \%)$ \\
\hline
\end{tabular}

which was the largest number of chronic obstructive pulmonary disease (COPD) cases, followed by historic pulmonary tuberculosis $(n=7)$ interstitial lung disease $(n=2)$, lung cancer $(\mathrm{n}=1)$ and asthma $(\mathrm{n}=1)$ (Table 2). The median chest tube drainage period after chemical pleurodesis was 5.04 days. The number of chemical pleurodesis ranged from one to four.

After the first pleurodesis, 20 achieved success, two cases after the second, two cases after the third, and one case after the fourth and thus, eventually all 25 patients showed improvement, following which the chest tube was removed and discharged from the hospital.

Adverse events associated with chemical pleurodesis included clinically meaningful complications such as fever $(n=7)$, moderate pain $(n=4)$, dyspnea with desaturation $(n=7)$, and leukocytosis $(\mathrm{n}=10)$. Patients with fever above $37.5^{\circ} \mathrm{C}$ received bedside cooling therapy with propacetamol, $1 \mathrm{~g}$ intravenous injection, and repeated every four hours but not exceeding $4 \mathrm{~g} /$ day if fever persisted. The fever lasted one or 2 days, and all the patients recovered without sequelae. Patients with moderate pain $(\mathrm{NRS}>5)$ were treated with propacetamol $1 \mathrm{~g}$ intravenous injection, and repeated if needed or administered morphine sulfate $5 \mathrm{mg} I V$ injection.
Patients with leukocytosis $\left(\mathrm{WBC}>10,000 / \mathrm{mm}^{3}\right.$ ) showed normalization of WBC counts without special management after 3 days. The most serious complication related to chemical pleurodesis was dyspnea with desaturation (saturation $<90 \%$ ). Patients who experienced this adverse event underwent oxygen therapy with a nasal prong cannula (3-5 liter/min), resulting in improvement of symptoms in most cases within 24 hours after chemical pleurodesis. Because all adverse events associated with chemical pleurodesis fell under Clavien-Dindo scale (12) grade 2, other than pharmacotherapy, no further management was needed (13). Recurrence of pneumothorax was found in two patients on days 210 and 375 after chemical pleurodesis during the 28-month follow-up. Chemical pleurodesis was repeated in both patients, which resulted in an improvement (Table 3).

\section{Discussion}

Viscum album is species that a parasitic plant called mistletoe, and it has been used as a medicinal herb all over Europe for thousands of years (14). In particular, it has been used to treat gynecological cancer (15).

In this study, we demonstrated that chemical pleurodesis using extracts from the mistletoe plant $V$. Album L. was effective against secondary spontaneous pneumothorax in patients $\geq 65$ of age.

Surgery is the most effective therapeutic approach for primary and recurrent spontaneous pneumothorax because surgical procedures are well established in patients whose general condition is often tolerable for surgery, which is facilitated by the relatively easy radiologic identification of the bullous portion in the lung that causes pneumothorax. However, patients who are unable to withstand the surgery (1), and in the case of secondary spontaneous pneumothorax, those whose lungs show severe emphysematous changes due to co-existing pulmonary disease, face an uphill task during preoperative radiological evaluation because of the difficultly in determining the area of surgical resection. Therefore, unlike primary spontaneous pneumothorax, even after surgery, there is a high risk for recurrence of pneumothorax in the remaining lungs. Old age, poor pulmonary function, and poor performance are the main risk factors for surgery. Hence, chemical pleurodesis may be appropriate for inoperable secondary spontaneous pneumothorax (1).

Nevertheless, caution must be exercised with chemical pleurodesis due to the adverse events associated with the 
Table 3 Results of chemical pleurodesis with Viscum album L. Number of pleurodesis: 1 time (20 cases), 2 times ( 2 cases), 3 times ( 2 cases), 4 time (1 case)

\begin{tabular}{|c|c|}
\hline Variable & Value \\
\hline $\begin{array}{l}\text { Chest tube indwelling period after chemical } \\
\text { pleurodesis (day), mean [range] }\end{array}$ & $5.04[2-12]$ \\
\hline Mean number of pleurodesis [range] & $1.36[1-4]$ \\
\hline \multicolumn{2}{|l|}{ Complication after chemical pleurodesis } \\
\hline Fever $>37.5$ & 7 \\
\hline Pain > NRS $5^{\star}(\mathrm{n} \%$, mean, SD) & 4 \\
\hline Leukocytosis $>10,000 / \mathrm{mm}^{3}$ & 10 \\
\hline Dyspnea with desaturation (< Sat. $\left.90 \%^{\star \star}\right)$ & 7 \\
\hline Mean follow-up period (months), mean [range] & $28.04[2-48]$ \\
\hline $\begin{array}{l}\text { Recurrent cases of pneumothorax after } \\
\text { chemical pleurodesis }\end{array}$ & 2 \\
\hline
\end{tabular}

procedure (1). Further, though various sclerosants have been used, the success rate of treating pneumothorax using chemical perfusion was lower by surgical interventions (16). Most sclerosants were initially used for the treatment of malignant pleural effusion, and later for the treatment of spontaneous pneumothorax (17-21). Tetracycline was the first attempted sclerosant for both primary and secondary pneumothorax based on animal studies $(2,3,20,22)$. This was followed by chemical pleurodesis with minocycline or doxycycline, that despite demonstrating significant efficacy, had disadvantages including adverse effects, high cost and insufficient quantities of the antibiotics., Others reported effective treatment of secondary spontaneous pneumothorax by chemical pleurodesis using iodopovidone, OK-432 and autologous blood $(4,5,23,24)$.

The most effective sclerosant is talc (25-27), which is inexpensive and easily available compared to other sclerosants (7-9). Chemical pleurodesis using talc, in the form of slurry or powder is used for bedside or surgery, respectively, with similar success rates for the management of secondary spontaneous pneumothorax (20). However, an adverse effect associated with the use of talc is acute pneumonia that can exacerbate to acute respiratory distress syndrome (27). There is no clear mechanism for this, but it is probably due to the various sizes and types of talc parts $(28,29)$.

Also, in the case of talc powder, very careful attention is required when applying it because it can cause cancers (30,31). Viscum album L. extract has been used as an auxiliary herbal medication for cancer treatment for more than 80 years in Europe (32), particularly against malignant pleural effusion, after successful chemical pleurodesis with bleomycin $(2,10)$. Subsequently, extracts from $V$. Album L. were used in chemical pleurodesis of spontaneous pneumothorax $(10,11,33)$.

Despite the patient population examined in our study being of an older age, with comorbidities, chemical pleurodesis using $V$. Album L. was effective for secondary spontaneous pneumothorax. Nevertheless, adverse effects associated with the procedure included dyspnea with desaturation, which was treated by conservative oxygen therapy, and was attributed to the pain caused by pleural inflammation. Dyspnea with desaturation may have serious consequences if not properly managed.

Perhaps dyspnea is due to the patient's impaired pulmonary function worsening the inflammation of pleurodesis. Therefore, it is necessary to pay attention to dyspnea with desaturation that may occur after pleurodesis through tests such as Pulmonary function test or 5-minute walking test before Pleurodesis.

Successful chemical pleurodesis in all patients in this study may be due to severe pleural inflammation induced by $V$. Album L. Severe pleural inflammation may increase the success rate of pleurodesis, though adverse effects caused by severe pleural inflammation are also expected. For this reason, physicians should exert pain control measures when performing chemical pleurodesis with $V$. Album L. Due to the pain accompanying dyspnea with desaturation experienced by patients in this study, fentanyl regimen was administered to control intense pain.

This study is not without limitations. First, due to its retrospective nature, statistical corrections were made for missing information, which might have led to information bias. Second, this study comprised a relatively small number of cases from a single institution. Therefore, large prospective studies are needed to determine the efficacy and mechanism of chemical pleurodesis with $V$. Album L. for secondary spontaneous pneumothorax in elderly patients.

\section{Conclusions}

We demonstrated the successful use of chemical pleurodesis with $V$. Album L. for the management of secondary spontaneous pneumothorax in elderly patients. However, because of the high probability of dyspnea with desaturation 
in the elderly, caution must be exercised.

\section{Acknowledgments}

Funding: None.

\section{Footnote}

Reporting Checklist: The authors have completed the STROBE reporting checklist. Available at http://dx.doi. org/10.21037/jtd-20-708

Data Sharing Statement: Available at http://dx.doi. org/10.21037/jtd-20-708

Conflicts of Interest: All authors have completed the ICMJE uniform disclosure form (available at http://dx.doi. org/10.21037/jtd-20-708). The authors have no conflicts of interest to declare.

Ethical Statement: The authors are accountable for all aspects of the work in ensuring that questions related to the accuracy or integrity of any part of the work are appropriately investigated and resolved. The study was conducted in accordance with the Declaration of Helsinki (as revised in 2013). This study was approved by Institutional Review Board of Gyeongsang National University Medical Center (No. 2019-06-023) and informed consent was taken from all the patients.

Open Access Statement: This is an Open Access article distributed in accordance with the Creative Commons Attribution-NonCommercial-NoDerivs 4.0 International License (CC BY-NC-ND 4.0), which permits the noncommercial replication and distribution of the article with the strict proviso that no changes or edits are made and the original work is properly cited (including links to both the formal publication through the relevant DOI and the license). See: https://creativecommons.org/licenses/by-nc-nd/4.0/.

\section{References}

1. MacDuff A, Arnold A, Harvey J, et al. Management of spontaneous pneumothorax: British Thoracic Society Pleural Disease Guideline 2010. Thorax 2010;65:ii18-ii31.

2. Vargas FS, Wang NS, Lee HM, et al. Effectiveness of bleomycin in comparison to tetracycline as pleural sclerosing agents in rabbits. Chest 1993;104:1582-4.
3. Light RW, Wang NS, Sassoon CSH, et al. Comparison of the effectiveness of tetracycline and minocycline as pleural sclerosing agents in rabbits. Chest 1994;106:577-82.

4. Agarwal R, Aggarwal AN, Gupta D, et al. Efficacy and safety of iodopovidone pleurodesis through tube thoracostomy. Respirology 2006;11:105-8.

5. Evman S, Alpay L, Metin S, et al. The efficacy and economical benefit of blood patch pleurodesis in secondary spontaneous pneumothorax patients. Kardiochir Torakochirurgia Pol 2016;13:21-5.

6. Estrada Saló G, Farina Rios C, Fibla Alfara JJ, et al. Spontaneous pneumothorax: Pleurodesis with an iodopovidone hydroalcoholic solution. Arch Bronconeumol 2003;39:171-4.

7. Tschopp JM, Brutsche M, Frey JG. Treatment of complicated spontaneous pneumothorax by simple talc pleurodesis under thoracoscopy and local anesthesia. Thorax 1997;52:329-32.

8. Bridevaux PO, Bridevaux PO, Tschopp JM, et al. Shortterm safety of thoracoscopic talc pleurodesis for recurrent primary spontaneous pneumothorax: a prospective European multicenter study. Eur Respir J 2011;38:770-3.

9. Sahn SA. Talc should be used for pleurodesis. Am J respir Crit Care Med 2000;162:2023-4.

10. Lee YG, Jung I, Koo DH, et al. Efficacy and safety of Viscum album extract (Helixor-M) to treat malignant pleural effusion in patients with lung cancer. Support Care Cancer 2019;27:1945-9.

11. Eom JS, Ahn HY, Mok JH, et al. Pleurodesis using mistletoe extract delivered via a spray catheter during semirigid pleuroscopy for managing symptomatic malignant pleural effusion Pleurodesis Using Mistletoe Extract Delivered via a Spray Catheter during Semirigid Pleuroscopy for Managing Symptomatic Malignant Pleural Effusion. Respiration 2018;95:177-81.

12. Dindo D, Demartines N, Clavien PA. Classification of surgical complications: a new proposal with evaluation in a cohort of 6336 patients and results of a survey. Ann Surg 2004;240:205-13.

13. West JB. Distribution of mechanical stress in the lung, a possible factor in localization of pulmonary disease. Lancet 1971;1:839-41.

14. Zuber D. Biological flora of Central Europe: Viscum album L. Flora 2004;199:181-203.

15. Kienle GS, Glockmann A, Schink M, Kiene H. Viscum album L. extracts in breast and gynaecological cancers: a systematic review of clinical and preclinical research. J Exp Clin Cancer Res 2009;28:79. 
16. Salomaa ER, Pulkki K, Kelenius H. Pleurodesis with doxycycline or Corynebacterium parvum in malignant pleural effusion. Acta Oncol 1995;34:117-21.

17. Rafiei R, Yazdani B, Ranjbar SM, et al. Long-term results of pleurodesis in malignant pleural effusion; Doxycycline vs Bleomycin. Adv Biomed Res 2014;3:149.

18. Lumachi F, Mazza F, Ermani M, et al. Talc pleurodesis as surgical palliation of patients with malignant pleural effusion. Analysis of factors affecting survival. Anticancer Res 2012;32:5071-4.

19. Light RW, O'Hara VS, Moritz TE, et al. Intrapleural tetracycline for the prevention of recurrent spontaneous pneumothorax: results of a department of veterans affairs co-operation study. JAMA 1990;264:2224-30.

20. Watanabe T, Fukai I, Okuda K, et al. Talc pleurodesis for secondary pneumothorax in elderly patients with persistent air leak. J Thorac Dis 2019;11:171-6.

21. Chen JS, Chan WK, Yang PC. Intrapleural minocycline pleurodesis for the treatment of primary spontaneous pneumothorax. Curr Opin Pulm Med 2014;20:371-6.

22. Rinaldi S, Felton T, Bentley A. Blood pleurodesis for the medical management of pneumothorax. Thorax 2009;64:258-60.

23. Viallat JR, Rey F, Astoul P, et al. Thoracoscopic talc poudrage pleurodesis for malignant effusion; a review of 360 cases. Chest 1996;110:1387-93.

24. Kishi K, Homma S, Sakamoto S, et al. High efficacy of pleurodesis using OK-432 for controlling intractable pneumothorax associated with pulmonary

Cite this article as: Kim JD, Choi JW, Park HO, Lee CE, Jang IS, Choi JY, Kang DH, Jung JJ, Yang JH, Moon SH, Byun JH, Kim SH, Kim JW. Chemical pleurodesis with Viscum album L. extract for secondary spontaneous pneumothorax in elderly patients. J Thorac Dis 2020;12(10):5440-5445. doi: 10.21037/jtd20-708 lymphangioleiomyomatosis. Nihon Kokyuki Gakkai Zasshi 2003;41:704-7.

25. Tattersall M. Management of malignant pleural effusion. Aust N Z J Med 1998;28:394-6.

26. Walker-Renard PB, Vaughan LM, Saln SA. Chemical pleurodesis for malignant pleural effusion. Ann Intern Med 1994;120:56-64.

27. Brant A, Eaton T. Serious complications with talc slurry pleurodesis? Respirology 2001;6:181-5.

28. Ferrer J, Montes JF, Villarino MA, et al. Influence of particle size on extrapleural talc dissemination after talc slurry pleurodesis. Chest 2002;122:1018-27.

29. Shinno Y, Kage H, Chino H, et al. Old age and underlying interstitial abnormalities are risk factors for development of ARDS after pleurodesis using limited amount of large particle size talc. Respirology 2018;23:55-9.

30. Scholtze D, Rueegg CA. Pulmonary talc granulomatosis mimicking lung cancer. BMJ Case Rep 2019;12:e230180.

31. Chang CJ, Yang YH, Chen PC, et al. Stomach cancer and exposure to talc powder without asbestos via Chinese herbal medicine: A population-based cohort study. Int J Environ Res Public Health 2019;16:717.

32. Kienle GS, Kiene H. Influence of Viscum album L (European mistletoe) extracts on quality of life in cancer patients: a systematic review of controlled clinical studies. Integr Cancer Ther 2010;9:142-57.

33. Song KS, Keum D, Kim JB. Chemical pleurodesis using doxycycline and Viscum album extract. Korean J Thorac Cardiovasc Surg 2017;50:281-6. 